06

\title{
Отрицательные электроды для литий-ионных аккумуляторов, полученные фотоанодированием кремния солнечной градации
}

\author{
(С) Г.В. Ли, Е.В. Астрова, Н.Е. Преображенский, А.М. Румянцев, С.И. Павлов, Е.В. Берегулин
}

Физико-технический институт им. А.Ф. Иофрфе РАН,

194021 Санкт-Петербург, Россия

e-mail: GalyaFedulova@mail.ioffe.ru, east@mail.ioffe.ru

Поступило в Редакцию 11 мая 2018 г.

В окончательной редакции 26 ноября 2018 r.

Принято к публикации 5 декабря 2018 г.

Отрицательные электроды для литий-ионных аккумуляторов, изготовленные методом электрохимического травления монокристаллического кремния, демонстрируют высокие значения удельной емкости на грамм материала и на единицу номинальной площади анода, а также высокую стабильность в течение нескольких сотен и даже тысяч циклов. Однако промышленное использование подобного рода структур нецелесообразно, из-за высокой стоимости материала и используемой технологии. Исследованы аноды на основе неупорядоченных макропор в солнечном $n$-Si, полученные с помощью фотоанодирования в $4 \%$ растворе $\mathrm{HF}$ в диметилформамиде. Использование органического электролита приводит к формированию слоев с пористостью, более высокой, чем в водном электролите, и обеспечивает самопроизвольное отделение этих слоев от подложки. Из макропористых мембран толщиной $48-86 \mu \mathrm{m}$ с пористостью 52-75\% изготовлены аноды и исследованы их электрохимические характеристики. Установлено влияние геометрических параметров пористой структуры и режима испытаний на величину зарядной и разрядной емкости и на длительность работы анодов. В режиме ограничения зарядной емкости величиной $1000 \mathrm{~mA} \cdot \mathrm{h} / \mathrm{g}$ и скорости заряда/разряда $C / 5$ полученные аноды способны стабильно работать в течение нескольких сотен циклов, сохраняя высокую (более 98\%) кулоновскую эффективность.

DOI: 10.21883/JTF.2019.05.47473.193-18

\section{Введение}

Кремниевые структуры, полученные методом электрохимического травления, являются перспективным материалом для анодов литий-ионных аккумуляторов [1-5]. При использовании Si-структурных элементов (наностенок или нанопроволок) нужного размера, ограничении количества лития, внедряемого в электрод, и оптимальных токов заряда/разряда кремниевые аноды стабильно работают в составе полуячейки [6-8]. Разработанная нами ранее технология получения упорядоченных $3 D$-структур с тонкими монодисперсными стенками [810] позволила получать аноды, не проявляющие признаков деградации в течение более 1200 циклов при удельной емкости $1000 \mathrm{~mA} \cdot \mathrm{h} / \mathrm{g}$ и демонстрирующие кулоновскую эффективность на уровне 98-100\% (за исключением первых нескольких циклов). Однако промышленное использование таких анодов ограничено их себестоимостью, которая в первую очередь определяется использованием монокристаллического кремния, предназначенного для микроэлектроники, а также наличием таких дорогих процессов в технологии, как фотолитография. Кремневые пластины солнечной градации доступны на рынке по цене за грамм, в 10 раз меньшей, и обладают высоким временем жизни неосновных носителей, что немаловажно для фототравления. Кроме того, формирование неупорядоченной решетки макропор не предполагает использование фотолитографии. В работе [11] было исследовано формирование макропористых слоев и мембран из $n-\mathrm{Si}$, предназначенного для солнечной энергетики. Целью настоящей работы явилось изучение электрохимических характеристик анодов, полученных из этих мембран.

\section{Эксперимент}

Исходным материалом для анодирования служили пластины монокристаллического кремния n-типа солнечной градации. Пластины толщиной $180 \mu \mathrm{m}$, ориентированные в плоскости (100), имели удельное сопротивление $3 \Omega \cdot \mathrm{cm} \quad\left(N_{d}=1.7 \cdot 10^{15} \mathrm{~cm}^{-3}\right)$ и обладали текстурированной поверхностью, пирамидки на поверхности которой сохранялась и после анодирования (рис. 1). Электрохимическое травление образцов размером $27 \times 27 \mathrm{~mm}$ проводилось на установке SiPor фирмы ET\&TE в электролите, состоящем из $4 \%$ раствора

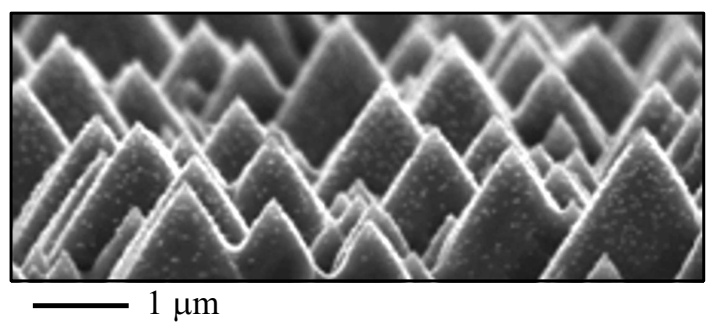

Рис. 1. Текстурированная поверхность образца после анодирования. 

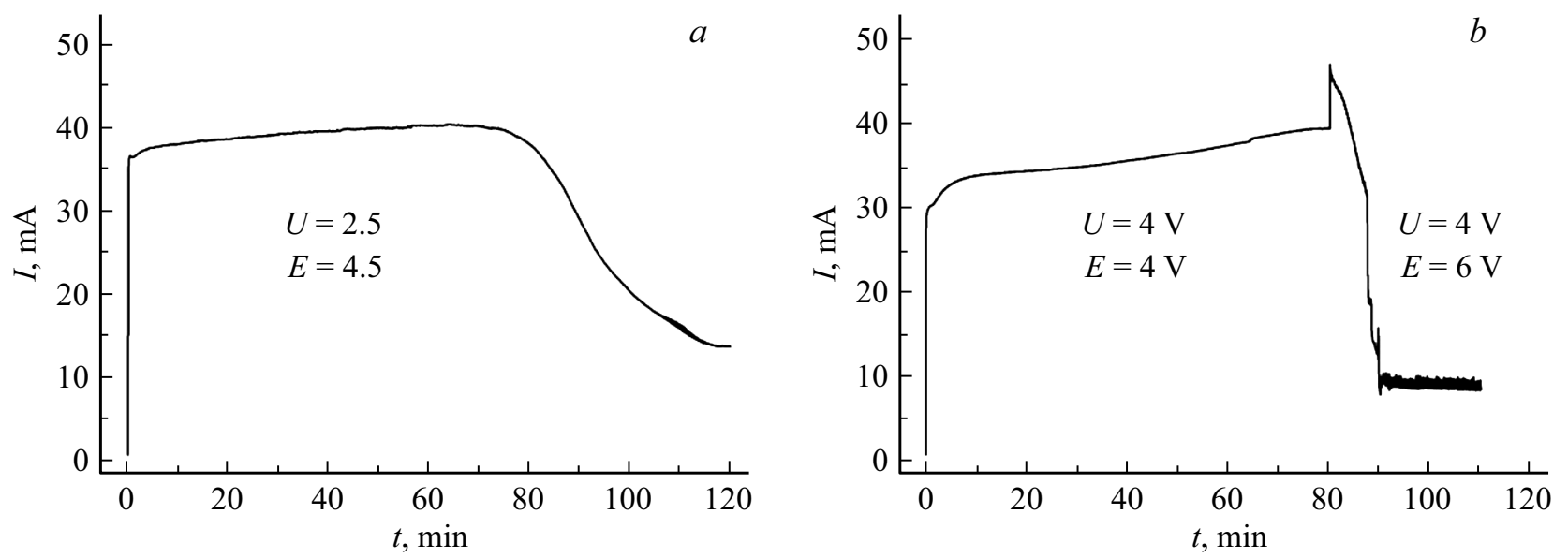

Pис. 2. Зависимость тока от времени при анодировании образцов 21-04-N1 (a) и 15-03-N1 (b).

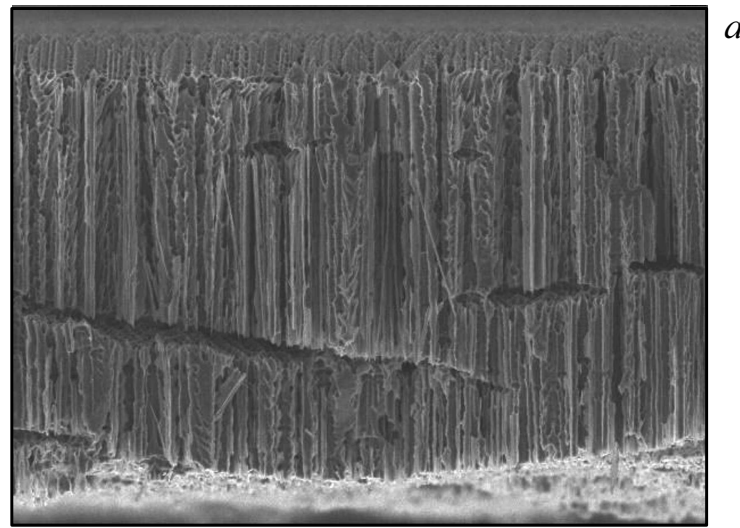

$\longrightarrow 10 \mu \mathrm{m}$

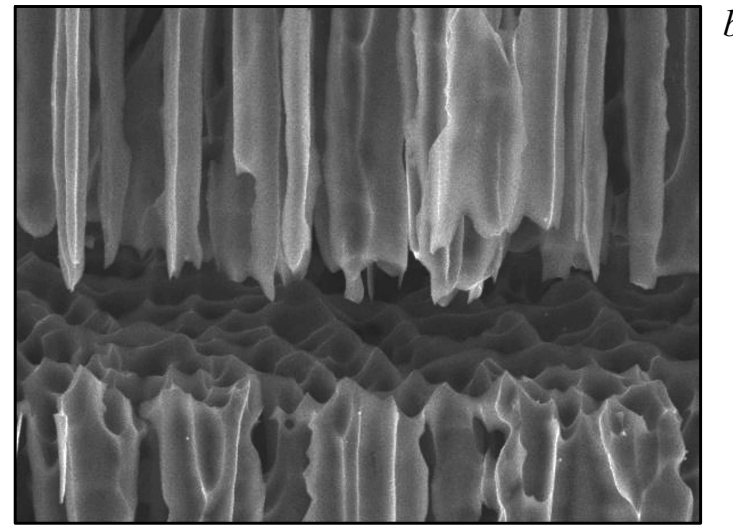

$-1 \mu \mathrm{m}$

Рис. 3. Образование полостей в пористой мембране: $a, b$ - SEM-изображение поперечного сечения образца 21-04-N2.

HF в диметилформамиде (ДМФ). Процесс проводился при $T=22^{\circ} \mathrm{C}$ в условиях освещения обратной стороны образца светом с длиной волны $\lambda=0.88 \mu \mathrm{m}$. Фотоанодированию подвергалась область диаметром $18 \mathrm{~mm}$. Анодирование осуществлялось в потенциостатическом режиме при разном напряжении (подробнее технология описана в работе [11]). В табл. 1 приведены режимы анодирования и характеристики полученных пористых структур, где $U-$ напряжение на границе кремнийэлектролит, $E-$ интенсивность подсветки, пропорциональная напряжению на матрице светодиодов, $p-$ гравиметрическая пористость мембраны, измеренная после отделения ее от подложки, $l$ - толщина мембраны, а $a-$ среднее расстояние между порами. Отделение макропористой мембраны от подложки происходило за счет перехода в режим электрополировки. Типичная зависимость тока анодирования от времени приведена на рис. 2. На ней имеется линейно возрастающий участок тока, характерный для порообразования, после которого следует спадающий участок, обусловленный появлением полостей в пористом кремнии, а затем и полным отделением мембраны от подложки (рис. 3).

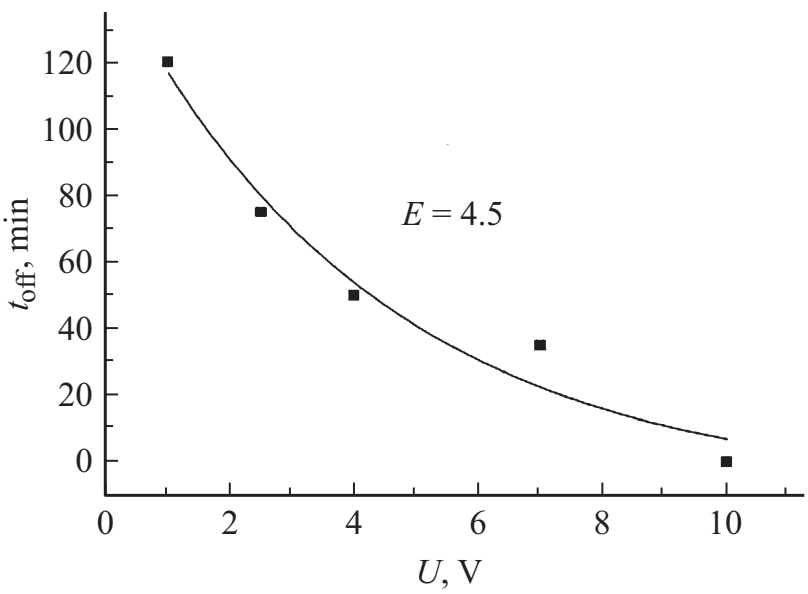

Рис. 4. Зависимость времени $t_{\text {off }}$, необходимого для начала отделения пористого слоя от подложки, от напряжения.

Из табл. 1 видно, что при напряжении $U<4 \mathrm{~V}$ плотность пор возрастает с напряжением ( $a$ уменьшается), а при $U>4 \mathrm{~V}$ остается практически неизменной. 
Таблица 1. Режимы фотоанодирования (4\% $\mathrm{HF}$ в ДМФ) и параметры пористых слоев

\begin{tabular}{c|c|c|c|c|c|c|c|c}
\hline № анода & Образец & $U, \mathrm{~V}$ & $E, \mathrm{~V}$ & $t, \min$ & $l, \mu \mathrm{m}$ & $p, \%$ & $a, \mu \mathrm{m}$ & $t_{\text {off, }} \min$ \\
\hline- & $13-04-\mathrm{N} 2$ & 1 & 4.5 & 120 & 98 & 40.2 & 3.2 & $>120$ \\
$3-8$ & $21-04-\mathrm{N} 1$ & 2.5 & 4.5 & 120 & 86 & $\left.55.3 / 74.6^{*}\right)$ & 1.4 & 75 \\
$9-7$ & $14-04-\mathrm{N} 1$ & 4 & 4.5 & 120 & 66 & 62.4 & 0.95 & 50 \\
$5-7$ & $21-04-\mathrm{N} 2$ & 7 & 4.5 & 120 & 48 & 68.6 & 1.05 & 35 \\
- & $12-04-\mathrm{N} 1$ & 10 & 4.5 & 60 & 0 & 100 & - & 0 \\
$1-8$ & $15-03-\mathrm{N} 1$ & 4 & 4 & 80 & 76 & 52.1 & 1.0 & $>80$
\end{tabular}

Примечан и.$~ t t_{\text {off }}$ - время до начала отделения пористого слоя от подложки,${ }^{*)}-$ пористость после дополнительной обработки в КОН.

Обычно отделение пористого слоя происходило самопроизвольно, причем время до начала отделения уменьшалось по мере увеличения напряжения $U$ (рис. 4), что сопровождалось уменьшением толщины мембраны $l$. Из величины тока $I=40 \mathrm{~mA}$, при котором это происходило, можно оценить критическую плотность тока, соответствующую переходу к четырехвалентному растворению кремния (электрополировке) $j_{P S}=15.7 \mathrm{~mA} / \mathrm{cm}^{2}$. Это значение примерно в 2 раза меньше, чем $j_{P S}$ для водного электролита с тем же содержанием HF [12]. Повидимому, этим обусловлена более высокая пористость слоев, полученных фотоанодированием в ДМФ, по сравнению с водным электролитом.

Образец 15-03-N1 анодировали в комбинированном режиме: $80 \mathrm{~min}$ при $U=4 \mathrm{~V}$ и $E=4$, а затем, чтобы произошло отделение, интенсивность света увеличивали до $E=6$. Из табл. 1 следует, что при $U \geq 10 \mathrm{~V}$ или при высокой интенсивности подсветки $(E=6)$ травление сразу переходит в режим электрополировки.

\section{Электрохимические характеристики анодов}

Для изготовления анодов из приведенных в табл. 1 образцов были выбраны те, что имеют наиболее высокую пористость. На верхнюю поверхность мембраны с помощью вакуумного термического напыления наносилась медь с подслоем хрома, а затем гальванически осаждался слой меди толщиной $7-15 \mu \mathrm{m}$ из раствора на основе медного купороса с добавлением небольших количеств серной кислоты и этанола. Плотность тока осаждения составляла $5-10 \mathrm{~mA} / \mathrm{cm}^{2}$, время осаждения 300-480 min. Образец 21-04-N1 до нанесения гальванической меди был подвергнут дополнительной обработке в растворе $12.3 \% \mathrm{KOH}$ и изопропилового спирта при $T=30^{\circ}$ в течение $30 \mathrm{~min}$, в результате чего его пористость возросла, а толщина $\mathrm{Si}$ стенок уменьшалась.

Из мембран с гальваническим медным контактом вырезались электроды меньшей площади. Полученные аноды собирались в дисковые корпуса CR2032, где вторым электродом служил металлический литий. Полуячейки подвергались циклическим испытаниям в гальваностатическом режиме на стенде CT3008W-5V10mA (Neware).
В качестве электролита использовался коммерческий продукт TC-E918 (Tinci, КНР), представляющий собой $1 \mathrm{M}$ раствор LiPF6 в смеси EC/PC/DEC/EMC (этиленкарбонат, пропиленкарбонат, диэтилкарбонат, этилметилкарбонат). Режимы исследования электрохимических характеристик приведены в табл. 2. Заряд ограничивался величиной удельной емкости $Q_{\mathrm{ch}} \approx 1000 \mathrm{~mA} \cdot \mathrm{h} / \mathrm{g}$ и потенциалом относительно лития $V=10 \mathrm{mV}$. Таким образом, диапазон изменения напряжения лежал в интервале 10-2000 mV. При заряде срабатывало либо ограничение по емкости, либо по напряжению $10 \mathrm{mV}$. В последнем случае реальное время заряда оказывалось меньше, чем заданное.

Зарядно-разрядные кривые всех анодов имеют типичный вид (рис. $5, b$ ). Первый цикл заряда отличается от последующих, что связано с аморфизацией, происходящей при литировании кристаллического кремния [13]. Разрядная кривая первого цикла демонстрирует необратимые потери 7-18\%, это количество электричества было потрачено на реакцию восстановления электролита и формирование твердофазной пленки на поверхности электрода (SEI). Формирование SEI обычно заканчивается на 2-м-3-м цикле (при этом необратимые потери составляют $1.3-2.9 \%$ ). Кулоновская эффективность для последующих циклов была близка к $100 \%$.

На рис. 5, $a$ представлена зависимость удельной емкости разряда от числа циклов для анодов $9 \_7$ и $3 \_8$, a на рис. $5, b$ показаны зарядно-разрядные кривые для анода 9_7. В рамках испытания анодов было установлено влияние так называемой „формировки электрода“, которая представляла собой заряд или заряд/разряд анода на начальных циклах малым током. Так, анод 9_7 после сборки в ячейку сначала заряжался током $0.2 \mathrm{~A} / \mathrm{g}$ (цикл 0 в табл. 2). При этом в электрод практически не удалось внедрить литий, так как произошло быстрое падение напряжения до $10 \mathrm{mV}$. Причиной такого поведения является низкая скорость диффузии атомов лития в кристаллический кремний. В результате большей скорости восстановления лития, его частицы накапливаются на поверхности, что приводит к быстрому снижению поверхностного потенциала до $10 \mathrm{mV}$. Уменьшение на следующем цикле зарядного тока до $j=0.1 \mathrm{~A} / \mathrm{g}$ позволило значительно увеличить $Q_{\text {ch }}$, и далее анод стал способен заряжаться током $0.2 \mathrm{~A} / \mathrm{g}$ до заданного 

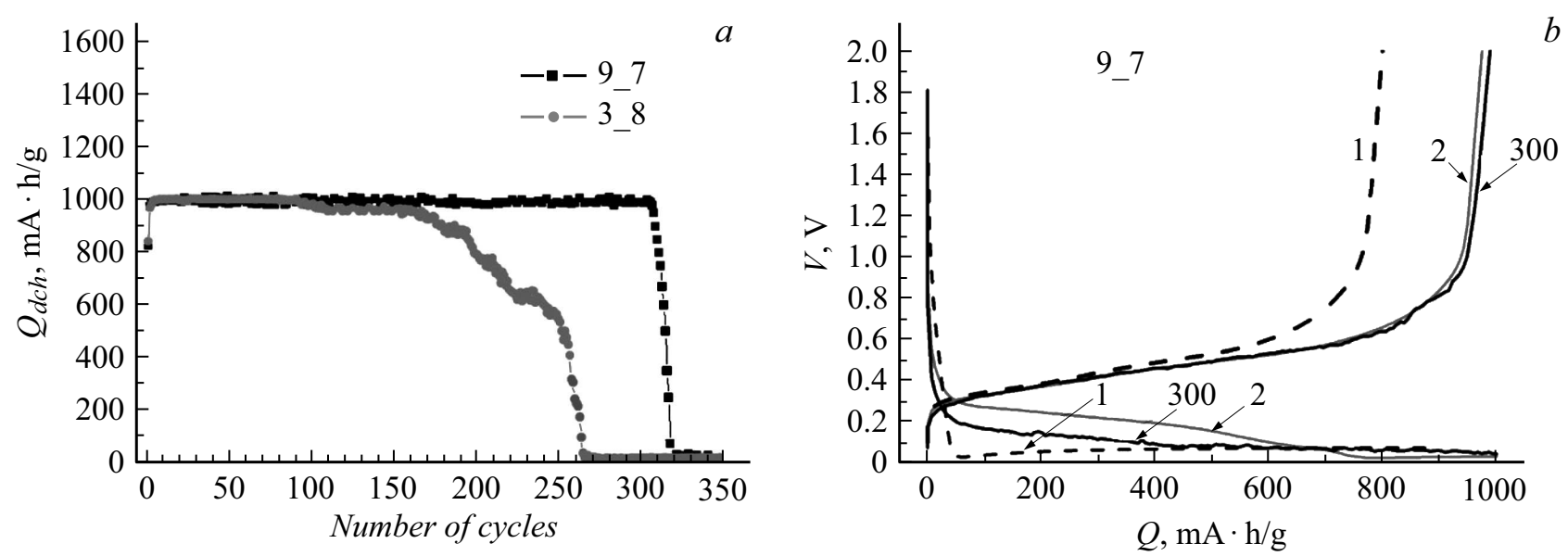

Рис. 5. $a$ - зависимость удельной емкости от числа циклов для образов 9_7 и 3_8; $b$ - зарядно-разрядные кривые образца 9_7; номера возле кривых указывают номер цикла.

Таблица 2. Параметры кремниевых анодов и режимы испытаний

\begin{tabular}{|c|c|c|c|c|c|c|c|c|c|}
\hline \multirow[t]{2}{*}{ № анода } & \multirow[t]{2}{*}{$\begin{array}{l}\text { Площадь } \\
S, \mathrm{~mm}^{2}\end{array}$} & \multirow[t]{2}{*}{ Macca, mg } & \multirow[t]{2}{*}{ № цикла } & \multicolumn{2}{|c|}{$\begin{array}{l}\text { Плотность } \\
\text { тока } j, \mathrm{~A} / \mathrm{g}\end{array}$} & \multicolumn{2}{|c|}{$\begin{array}{c}\text { Удельная емкость } Q, \\
\mathrm{~mA} \cdot \mathrm{h} / \mathrm{g}\end{array}$} & \multicolumn{2}{|c|}{ Время заряда, h } \\
\hline & & & & Заряда & Разряда & Заряда $Q_{\mathrm{ch}}$ & Разряда $Q_{\mathrm{dch}}$ & Заданное & Реальное \\
\hline $9-7$ & 7.09 & 0.41 & $\begin{array}{c}0 \\
1 \\
2-3 \\
4-310\end{array}$ & $\begin{array}{l}0.2 \\
0.1 \\
0.2 \\
0.2\end{array}$ & $\begin{array}{l}0.2 \\
0.2 \\
0.2 \\
0.2\end{array}$ & $\begin{array}{c}104 \\
896 \\
1000 \\
1000\end{array}$ & $\begin{array}{c}26 \\
800 \\
976-987 \\
1000\end{array}$ & $\begin{array}{r}5 \\
10 \\
5 \\
5\end{array}$ & $\begin{array}{l}0.52 \\
8.96 \\
5 \\
5\end{array}$ \\
\hline $3-8$ & 5.9 & 0.30 & $\begin{array}{c}1 \\
2-3 \\
4-100 \\
101-166 \\
167-267\end{array}$ & $\begin{array}{l}0.1 \\
0.1 \\
0.2\end{array}$ & $\begin{array}{l}0.1 \\
0.1 \\
0.2\end{array}$ & $\begin{array}{c}1000 \\
1000 \\
1000 \\
966-956 \\
936-40\end{array}$ & $\begin{array}{c}842 \\
971-984 \\
1000 \\
966-956 \\
936-40\end{array}$ & $\begin{array}{r}10 \\
10 \\
5 \\
5 \\
5\end{array}$ & $\begin{array}{c}10 \\
10 \\
5 \\
4.83-4.78 \\
4.68-0.2\end{array}$ \\
\hline $1-8$ & 18.27 & 1.55 & $\begin{array}{c}1 \\
2 \\
3-38 \\
39-102 \\
103-105 \\
106-108 \\
109-111 \\
112-165\end{array}$ & $\begin{array}{l}0.05 \\
0.2 \\
0.1 \\
0.2 \\
0.4 \\
0.8 \\
0.1\end{array}$ & $\begin{array}{l}0.2 \\
0.2 \\
0.1 \\
0.2 \\
0.4 \\
0.8 \\
0.1\end{array}$ & $\begin{array}{c}952 \\
810 \\
740 \\
1000 \\
740 \\
32 \\
4 \\
1000\end{array}$ & $\begin{array}{c}889 \\
793 \\
740 \\
1000 \\
740 \\
32 \\
4 \\
1000\end{array}$ & $\begin{array}{l}20 \\
5 \\
5 \\
10 \\
5 \\
2.5 \\
1.25 \\
10\end{array}$ & $\begin{array}{l}19.04 \\
4.05 \\
3.70 \\
10 \\
3.70 \\
0.08 \\
0.005 \\
10\end{array}$ \\
\hline $5-7$ & 10.25 & 0.36 & $\begin{array}{c}1 \\
2 \\
3 \\
4-65 \\
66-68 \\
69-71 \\
72-74 \\
75-77 \\
78-160\end{array}$ & $\begin{array}{l}0.1 \\
0.2 \\
0.1 \\
0.2 \\
0.4 \\
0.8 \\
0.1 \\
0.2\end{array}$ & $\begin{array}{l}0.2 \\
0.2 \\
0.1 \\
0.2 \\
0.4 \\
0.8 \\
0.1 \\
0.2\end{array}$ & $\begin{array}{c}1000 \\
1000 \\
846 \\
1000 \\
1000 \\
592 \\
120 \\
1000 \\
1000\end{array}$ & $\begin{array}{c}828 \\
945 \\
833 \\
1000 \\
1000 \\
592 \\
120 \\
1000 \\
1000\end{array}$ & $\begin{array}{c}10 \\
10 \\
5 \\
10 \\
5 \\
2.5 \\
1.25 \\
10 \\
5\end{array}$ & $\begin{array}{l}10 \\
10 \\
4.23 \\
10 \\
5 \\
1.48 \\
0.15 \\
10 \\
5\end{array}$ \\
\hline
\end{tabular}

$Q_{\mathrm{ch}}=1000 \mathrm{~mA} \cdot \mathrm{h} / \mathrm{g}$, демонстрируя стабильную работу в течение 310 циклов.

Образец 3_8 прошел формировку током $j=0.1 \mathrm{~A} / \mathrm{g}$ в течение первых трех циклов и далее стабильно циклировался при $j=0.2 \mathrm{~A} / \mathrm{g}$, заряжаясь до заданной емкости, в течение 100 циклов. Однако затем его зарядная и соответственно разрядная емкости стали постепенно уменьшаться, а начиная со 167 цикла анод начал резко деградировать. Таким образом, несмотря на меньшую пористость, образец 9_7 выдерживает большее число 


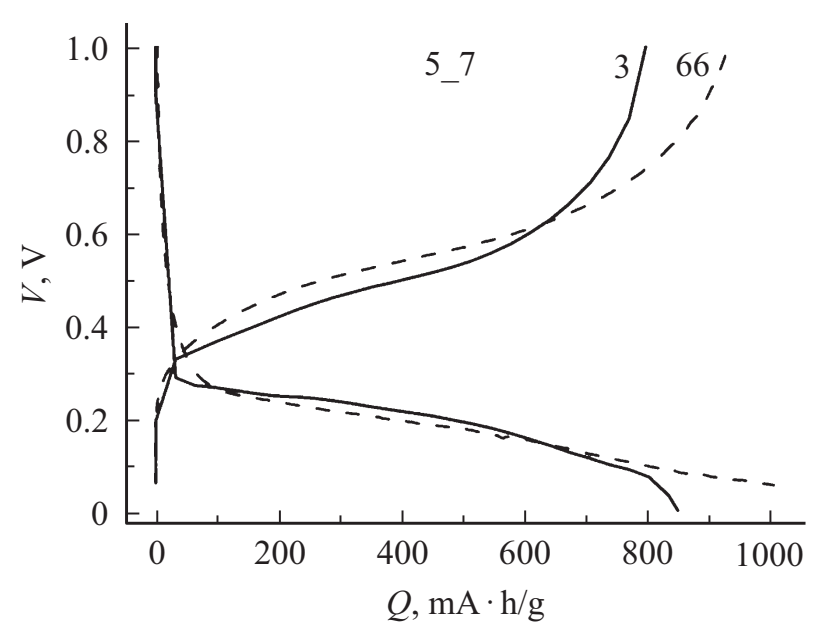

Рис. 6. Зарядно-разрядные кривые образца 5_7. Номера возле кривых указывают номер цикла.

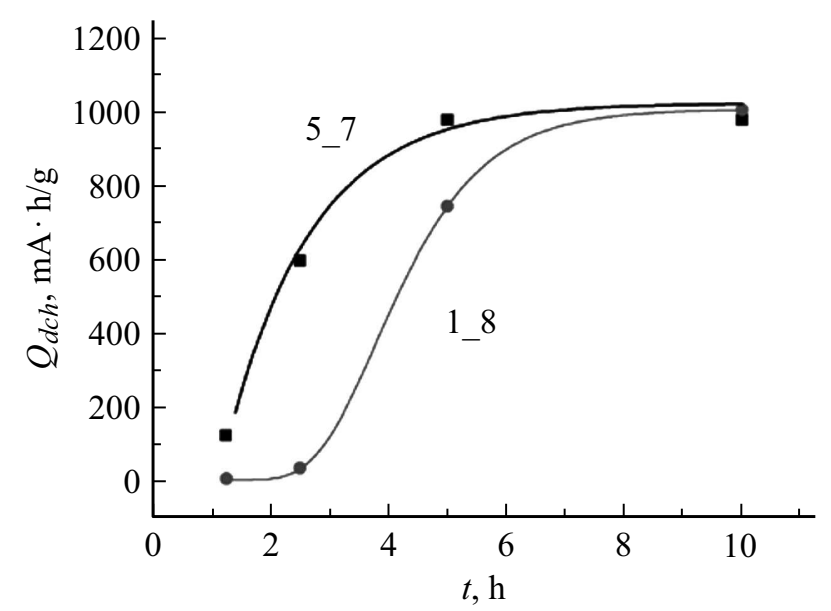

Рис. 7. Зависимость разрядной емкости от длительности полуцикла для анодов 5_7 и 1_8.

циклов. Возможно, это связано с более высокой плотностью пор на единицу плоской поверхности электрода и соответственно меньшей толщиной стенок. Не исключено, что влияет и меньшая толщина мембраны (табл. 1), которая, как было показано в [14], более равномерно литируется по глубине.

Аналогичная картина по влиянию формировки наблюдалась нами и для анода 5_7. Так, ток $j=0.1 \mathrm{~A} / \mathrm{g}$ на первых двух циклах позволял заряжать анод до заданной емкости. Разрядная емкость в этом случае демонстрирует типичную картину: емкость разряда на втором цикле больше, чем на первом, в результате того, что на первом цикле происходит образование SEI. На третьем цикле внедрение лития осуществлялось в два раза большим током $j=0.2 \mathrm{~A} / \mathrm{g}$ (заданное время $5 \mathrm{~h}$ ). Как видно из рис. 6 , в этом случае после достижения емкости $800 \mathrm{~mA} \cdot \mathrm{h} / \mathrm{g}$ напряжение начинает быстро падать, достигая $10 \mathrm{mV}$. Такая ступенька на зарядной кривой свидетельствует об образовании новой фазы с высоким содержанием лития. Начиная с 4-го цикла, анод заряжали и разряжали током $j=0.1 \mathrm{~A} / \mathrm{g}$. Переход на 66-м-68-м цикле снова на ток $j=0.2 \mathrm{~A} / \mathrm{g}$ уже не приводил к появлению ступеньки и не сопровождался уменьшением $Q_{\text {ch }}$, как это было на цикле № 3. По-видимому, это связано с тем, что по мере увеличения числа циклов усиливается разупорядочение кристаллической решетки, и аморфизация структуры происходит по всей глубине, а в аморфном материале скорость диффузии лития выше. После испытания работоспособности при разных токах на циклах 69-77 электрод продолжили заряжать и разряжать током $j=0.2 \mathrm{~A} / \mathrm{g}$. На момент написания настоящей работы он прошел 160 циклов заряда/разряда. Аналогично ведет себя и анод $1 \_8$, но полностью зарядить его можно было только за $10 \mathrm{~h}(j=0.1 \mathrm{~A} / \mathrm{g})$.

Для оценки зависимости разрядной емкости от скорости заряда/разряда на анодах 5_7 и 1_8 после 65-го и 102-го циклов соответственно ток увеличивали так, что скорость составляла $C / 5, C / 2.5$ и $C / 1.25$, и затем снова возвращалась на $C / 10$, где $C$ - заданная зарядная емкость. Из графика на рис. 7 видно, что анод 5_7 позволяет использовать большие скорости заряда, чем анод 1_8. Оба анода не могут заряжаться со скоростью $C / 1.25$. Сравнивая параметры структуры анодов $5 \_7$ и 1_8, можно видеть, что они отличаются толщиной мембраны и пористостью. Большей пористости анода 5_7 соответствуют более тонкие стенки и более высокая площадь внутренней поверхности, что может служить причиной снижения плотности тока на единицу площади.

\section{Заключение}

Таким образом, технология изготовления макропористых кремниевых анодов может быть существенно удешевлена за счет использования солнечного кремния. Электрохимические испытания, проведенные в режиме ограничения зарядной емкости $1000 \mathrm{~mA} \cdot \mathrm{h} / \mathrm{g}$, демонстрируют средние скорости заряда/разряда $C / 5$ или $C / 10$. Их емкость на единицу номинальной площади электрода составляет $3.5-8.5 \mathrm{~mA} \cdot \mathrm{h} / \mathrm{cm}^{2}$, а ресурс работы в составе полуячейки составляет несколько сотен циклов при высокой кулоновской эффективности.

Работа выполнена с использованием приборной базы ЦКП „Материаловедение и диагностика в передовых технологиях“ ФТИ им. А.Ф. Иоффе.

\section{Список литературы}

[1] Fóll H., Hartz H., Ossei-Wusu E., Carstensen J., Riemenschneider O. // Phys. Stat. Solid. RRL. 2010. Vol. 4. N 1-2. P. 4-6.

[2] Астрова Е.В., Федулова Г.В., Смирнова И.А., Ременюк А.Д., Кулова Т.Л., Скундин А.М. // Письма в ЖТФ. 2011. Т. 37. Вып. 15. С. 87-94. 
[3] Thakur M., Pernites R.B., Nitta N., Isaacson M., Sinsabaugh S.L., Wong M.S., Biswal S.L. // Chem. Mater. 2012. Vol. 24. N 15. P. 2998-3003.

[4] Thakur M., Sinsabaugh S.L., Isaacson M.J., Wong M.S., Biswal S.L. // Scientific Reports. 2012. Vol. 2. N 795. P. 1-7.

[5] Luais E., Sakai J., Desplobain S., Gautier G., Tran-Van F., Ghamouss F. // J. Power Sources. 2013. Vol. 242. P. 166-170.

[6] Quiroga-González E., Carstensen J., Föll H. // Energies. 2013. Vol. 6. P. 5145-5156.

[7] NÓhren S., Quiroga-Gonzalez E., Carstensen J., Föll H. // J. Electrochem. Society. 2016. Vol. 163. N 3. P. A373-A379.

[8] Li G.V., Rumyantsev A.M., Levitskii V.S., Beregulin E.V., Zhdanov V.V., Terukov E.I., Astrova E.V. // Semicond. Sci. Technol. 2016. Vol. 31. P. 014008.

[9] Ли Г.В., Астрова Е.В., Румянцев А.М., Воронков В.Б., Парфеньева А.В., Толмачев В.А., Кулова Т.Л., Скундин А.М. // Электрохимия. 2015. Т. 51. № 10. С. 1020-1029.

[10] Астрова Е.В., Ли Г.В., Румянцев А.М., Жданов В.В. // ФТП. 2016. Т. 50. Вып. 2. С. 279-286.

[11] Астрова Е.В., Преображенский Н.Е., Ли Г.В., Павлов С.И. // ФТП. 2018. Т. 52. Вып. 3. С. 414-430.

[12] Lehmann $V$. Electrochemistry of Silicon. Weinheim: WileyVCH, 2002. Ch.9. P. 183.

[13] Kasavajjula U., Wang C., Appleby A.J. // Power Sources. 2007. Vol. 163. P. 1003-1039.

[14] Астрова Е.В., Ли Г.В., Парфеньева А.В., Румянцев А.М., Жданов В.В., Павлов С.И., Левицкий В.С., Теруков Е.И., Давыдов В.Ю. // ЖТФ. 2015. Т. 85. Вып. 4. С. 52-61. 